\title{
$\omega$-Conotoxin GVIA Binding to a High-Affinity Receptor in Brain: Characterization, Calcium Sensitivity, and Solubilization
}

\author{
John A. Wagner, ${ }^{1}$ Adele M. Snowman, ${ }^{1}$ Amitava Biswas, ${ }^{1}$ Baldomero M. Olivera, ${ }^{2}$ and Solomon H. Snyder ${ }^{1}$ \\ ${ }^{1}$ Departments of Neuroscience, Pharmacology and Molecular Sciences, and Psychiatry and Behavioral Sciences, The \\ Johns Hopkins University School of Medicine, Baltimore, Maryland 21205, and 'Department of Biology, The University of \\ Utah, Salt Lake City, Utah 84112
}

\begin{abstract}
We describe unique, high-affinity binding sites for $\omega\left[{ }^{125}\right]$ conotoxin GVIA in membranes from rat brain and rabbit sympathetic ganglia which appear to be primarily associated with $\mathrm{N}$-type voltage-dependent calcium channels. The dissociation constant $\left(K_{D}\right)$ for the toxin in rat brain membranes is $60 \mathrm{pM}$. Physiologic extracellular concentrations of calcium inhibit toxin binding noncompetitively $\left(1 \mathrm{C}_{50}=0.2 \mathrm{~mm}\right)$. The regional distribution of the binding sites in rat brain differs markedly from that of dihydropyridine calcium antagonist receptors associated with L-type calcium channels. In detergent-solubilized brain membranes, toxin binding retains the same affinity, specificity, and ionic sensitivity as in particulate preparations.
\end{abstract}

Several subtypes of voltage-sensitive calcium channels are responsible for major functions of excitable tissues (Nilius et al., 1985; Nowycky et al., 1985). Calcium antagonist drugs of the dihydropyridine, phenylalkylamine, and benzothiazepine classes interact with the L subtype (Nowycky et al., 1985). The N subtype plays a role in neurotransmitter release in the brain (Miller, 1987). The role of T channels is not clear. The snail toxin $\omega$-conotoxin GVIA ( $\omega$-CTX) interacts potently and persistently with $\mathrm{N}$ and $\mathrm{L}$ channels but not $\mathrm{T}$ channels (McCleskey et al., 1987). The toxin also blocks PNS (Kobayashi et al., 1982; Keer and Yoshikami, 1984) and CNS (Reynolds et al., 1986) neurotransmission, presumably through an effect on $\mathrm{N}$ channels.

In earlier studies, saturable binding sites for $\omega\left[{ }^{125} \mathrm{I}\right] \mathrm{CTX}$ have been identified in chick brain synaptosomes (Cruz and Olivera, 1986; Cruz et al., 1987). However, the affinity of the binding sites was substantially less than the toxin's potency in blocking transmitter release, and calcium only had weak effects on binding. In another study, rat brain synaptic membranes were used to demonstrate $2 \omega\left[{ }^{125}\right.$ I]CTX binding sites (Abe et al., 1986). This study also used a toxin of relatively low specific activity. In the present study employing $\omega\left[{ }^{125} I\right] C T X$ of high specific activity, we have demonstrated a single binding site in rat brain membranes with low picomolar affinity, characterized its regional localization, demonstrated sensitivity to physiological

\footnotetext{
Received Sept. 22, 1987; revised Jan. 11, 1988; accepted Jan. 14, 1988.

We thank Dawn C. Dodson for manuscript preparation. This work was supported by USPHS Grants MH-18501 and Research Scientist Award DA-00074 to S.H.S. J.A.W. was supported by a National Science Foundation Graduate Fellowship.

Correspondence should be addressed to Solomon H. Snyder, M.D., Department of Neuroscience, The Johns Hopkins University School of Medicine, 725 North Wolfc Strcet, Baltimorc, MD 21205.

Copyright (C) 1988 Society for Neuroscience $0270-6474 / 88 / 093354-06 \$ 02.00 / 0$
}

extracellular calcium concentrations, and solubilized the receptor binding sites.

\section{Materials and Methods}

Materials. CTX GVIA was obtained from Peninsula (Belmont, CA) and iodinated as described (Olivera et al., 1984) by Russel Garlick (NEN/ DuPont, Boston). Specific activity of $\omega\left[{ }^{125} \mathrm{I}\right] \mathrm{CTX}$ was $2200 \mathrm{Ci} / \mathrm{mmol}$. Native $\omega$-CTX MVIIA was purified as described (Olivera et al., 1985) from the fish-hunting sea snail Conus magus, and native $\omega$-CTX GVIA was purified as described (Olivera et al., 1984) from Conus geographus. The phenylalkylamines, $(-)$-, (+)-desmethoxyverapamil and verapamil were gifts of Drs. Hollman and Traut (Knoll AG, Ludwigschaten, FRG). Nitrendipine was the gift of Dr. Alexander Scriabine (Miles Laboratories, New Haven, CT), and fostedil (KB 944) was a gift from Dr. Raymond Kauffman (E. Lilly, Indianapolis, IN). $\left[{ }^{3} \mathrm{H}\right]$ Nitrendipine $(78 \mathrm{Ci} /$ mmol) was obtained from NEN/DuPont (Boston). All other chemicals were obtained from commercial sources. Rabbit sympathetic ganglia were obtained frozen from Pel-Freez (Rogers, AR).

Preparation of rat whole forebrain, rat brain regions, and rabbit sympathetic ganglia. Rats (male Wistar rats, $175-250 \mathrm{gm}$ ) were sacrificed by cervical dislocation, their brains were rapidly removed, and dissected on ice. Frozen rabbit sympathetic ganglia were thawed. All further steps took place at $4^{\circ} \mathrm{C}$. Tissues were homogenized in $50 \mathrm{~mm}$ HEPES, pH $7.4,50 \mathrm{mg}$ wet weight tissue/ $\mathrm{ml}$ buffer, using a Brinkmann Polytron (setting on half-maximal for $30 \mathrm{sec}$ ). Homogenates were centrifuged for $15 \mathrm{~min}$ at $40,000 \times \mathrm{g}$. The pellet was resuspended in $50 \mathrm{~mm}$ HEPES, pH 7.4, $10 \mathrm{~mm}$ EDTA. Homogenates were incubated at $4^{\circ} \mathrm{C}$ for $30 \mathrm{~min}$ and recentrifuged at $40,000 \times g$ for $10 \mathrm{~min}$. The pellet was resuspended in Chelex-treated $50 \mathrm{~mm}$ HEPES, pH 7.4, using a Polytron for rat brain and sonicator for rabbit sympathetic ganglia.

Solubilization of $\left.\omega\right|^{125} I J C T X$ binding sites. CHAPS and Triton X-100 detergents, $0.1-2 \%$, were added to fresh crude membranes and homogenized with 8 strokes of a Teflon-glass homogenizer. After 30-60 min incubation at $4^{\circ} \mathrm{C}$, the homogenate was centrifuged at $100,000 \times g$ for $60 \mathrm{~min}$, and the supernatant was aspirated. In some experiments, the detergent-solubilized extracts were concentrated using an ultrafiltration apparatus (Amicon) at $50 \mathrm{psi}$. In other experiments, the pellet and supernatant were used immediately.

$\left.\omega I^{125} I\right] C T X$ binding assay. $\omega\left[{ }^{125} I\right] C T X$ was diluted from a lyophilized powder into double-distilled $\mathrm{H}_{2} \mathrm{O}$ and dispensed in $50 \mu \mathrm{l}$ aliquots into glass test tubes. Appropriate concentrations of crude or detergent-solubilized membranes, diluted into Chelex-treated 50 mM HEPES, $\mathrm{pH}$ 7.4 , were added to a total assay volume of $1 \mathrm{ml}$. Assays also contained $0.4 \%$ BSA and appropriate concentrations of drugs or ions dispensed in $1: 10$ or $1: 20$ dilutions. The final $\omega{ }^{125}$ I]CTX concentration was $15-$ $30 \mathrm{pm}$. At ligand concentrations above $60 \mathrm{pM}$, nonspecific binding increased more than specific binding so that routine assays also employed lower ligand concentrations. Mixtures were filtered simultaneously with a Brandel Cell Harvester (Gaithersburg, MD) using glass fiber filters (Scheicher and Schuell, No. 32) presoaked with the filtering buffer for crude membranes or $0.5 \%$ polyethylenimine for detergent-solubilized membranes. The filters then were washed at $4^{\circ} \mathrm{C}$ with three $4 \mathrm{ml}$ aliquots

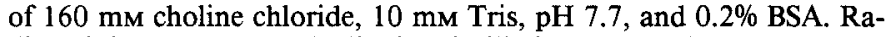
dioactivity was assessed by liquid scintillation spectrophotometry or by a gamma counter. $\left[{ }^{3} \mathrm{H}\right] \mathrm{Nitrendipine} \mathrm{binding} \mathrm{was} \mathrm{assayed} \mathrm{as} \mathrm{described}$ (Murphy et al., 1983). 


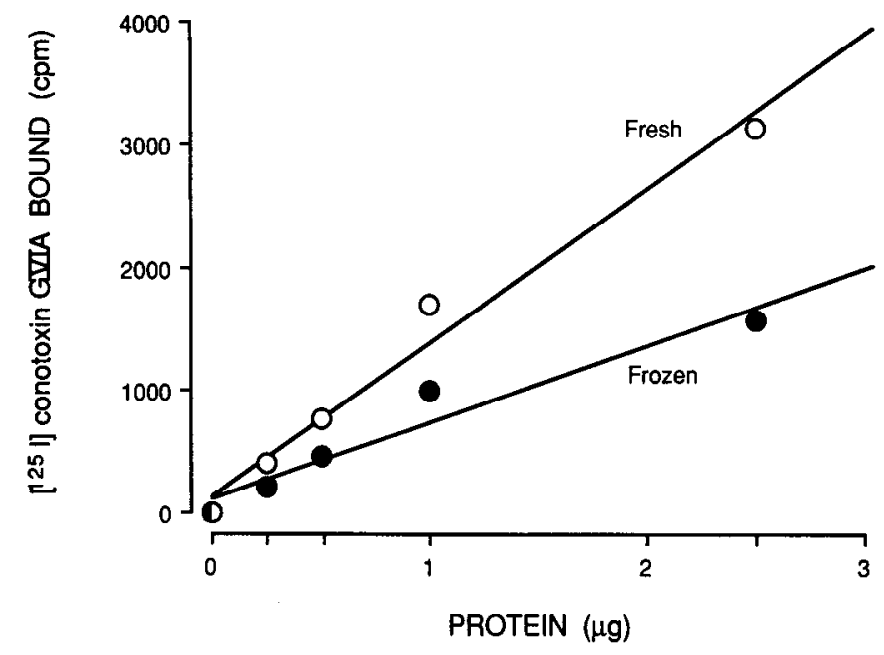

Figure 1. Membrane protein linearity of $\left.\omega^{\left[{ }^{125}\right.} \mathrm{I}\right] \mathrm{CTX}$ binding to rat forebrain membranes, both freshly prepared (open circles) and previously frozen at $-20^{\circ} \mathrm{C}$ ( filled circles). Ligand concentration was $28 \mathrm{pm}$ in this experiment. Individual points are means of duplicate determinations. This experiment was replicated 3 times with similar results.

\section{Results}

\section{General properties of $\omega$ [ $\left.^{125} I\right] C T X$ binding}

$\omega\left[{ }^{125} \mathrm{I}\right] \mathrm{CTX}$ binding to rat brain membranes is linear with tissue protein over the range $0.01-2.5 \mu \mathrm{g}$ (Fig. 1). Linearity of ligand binding with tissue is extremely dependent on the use of very low concentrations of tissue protein and low concentrations of ligand. Linearity is apparent only with tissue concentrations $<2$ $\mu \mathrm{g}$ protein $/ \mathrm{ml}$. Earlier studies in chick brain membranes employed higher tissue concentrations (Abe et al., 1986; Cruz and Olivera, 1986; Cruz et al., 1987).

$\omega\left[{ }^{125} \mathrm{I}\right] \mathrm{CTX}$ binding is temperature sensitive. At $25^{\circ} \mathrm{C}$ toxin binding reaches plateau levels by $7 \mathrm{~min}$, while about $20 \mathrm{~min}$ is required for equilibrium binding at $4^{\circ} \mathrm{C}$. Routine binding assays are conducted for $30 \mathrm{~min}$ at $25^{\circ} \mathrm{C}$. In typical experiments employing $1 \mu \mathrm{g}$ protein $/ \mathrm{ml}$ and $\left.20 \mathrm{pM} \omega{ }^{125} \mathrm{I}\right] C T X$, total binding is $3000 \mathrm{cpm}$ and nonspecific binding, measured in the presence of $0.1 \mu \mathrm{M}$ unlabeled toxin, is $1000 \mathrm{cpm}$.

Ligand binding is not markedly dependent upon $\mathrm{pH}$, with similar levels of equilibrium binding observed over the range of $\mathrm{pH} 7-8.9$.

$\omega\left[{ }^{125} \mathrm{I}\right] \mathrm{CTX}$ binding deteriorates with storage of rat brain membranes. If tissue is frozen at $-20^{\circ} \mathrm{C}$ immediately upon preparation of the membranes and thawed and assayed $24 \mathrm{hr}$ later, binding is reduced by $50 \%$ (Fig. 1). Accordingly, fresh brain tissue is employed for routine experiments.

\section{Saturation and kinetics of $\omega{ }^{125}$ IJCTX binding}

$\omega\left[{ }^{125} \mathrm{I}\right] \mathrm{CTX}$ is saturable (Fig. 2). At $25^{\circ} \mathrm{C}$ binding is half-maximal at $50 \mathrm{pm}$ unlabeled toxin. Scatchard analysis reveals a single population of binding sites with a dissociation constant $\left(K_{D}\right)$ of $60 \mathrm{pM}$ and a maximal number of binding sites $\left(R_{\max }\right)$ of about $3 \mathrm{pmol} / \mathrm{mg}$ protein.

$\omega\left[{ }^{125} \mathrm{I}\right] \mathrm{CTX}$ associates fairly rapidly and dissociates quite slowly (Fig. 3). At $25^{\circ} \mathrm{C}$ binding reaches plateau levels at $3-4 \mathrm{~min}$ and half-maximal levels at $0.5 \mathrm{~min}$ (Fig. $3 A$ ). The plot of time versus In $\left(B_{e} / B_{e}-B\right)$ is linear, consistent with a simple bimolecular reaction. The $k_{\mathrm{ob}}$ is $0.784 \mathrm{~min}^{-1}$, and the calculated rate constant for association $\left(k_{1}\right)$ is $2.6 \times 10^{10} \mathrm{~min}^{-1} \mathrm{M}^{-1}$. The $K_{\mathrm{ob}}$ for $\omega\left[{ }^{[25 I}\right] \mathrm{CTX}$ at $4^{\circ} \mathrm{C}$ is $0.2 \mathrm{~min}^{-1}$.

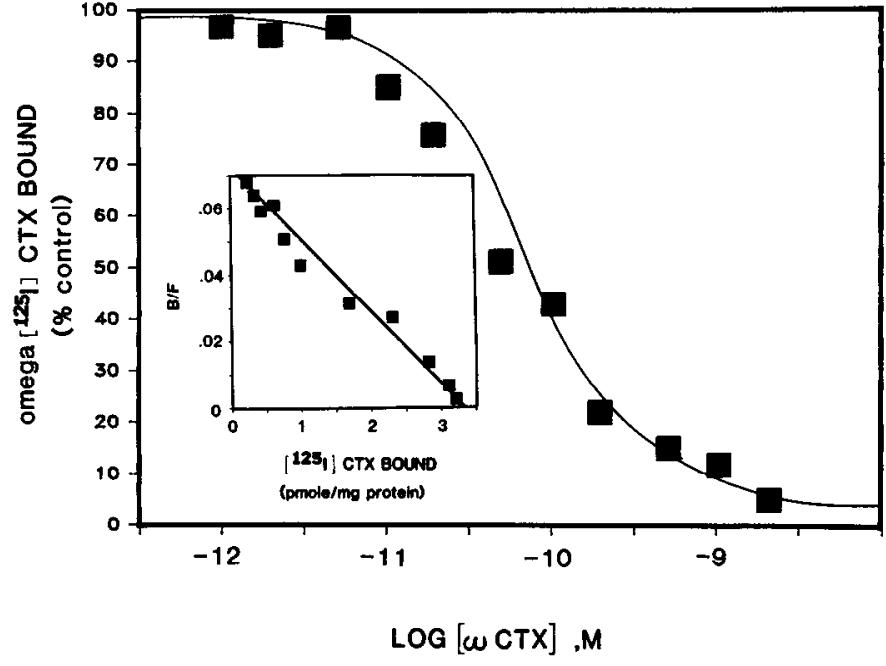

Figure 2. Saturation analysis of $\omega\left[{ }^{125} I\right] \mathrm{CTX}$ binding to rat forebrain membranes. $\omega\left[{ }^{125} \mathrm{I}\right] \mathrm{CTX}, 24 \mathrm{pM}$, was incubated with the indicated concentrations of unlabeled toxin in triplicate. Inset, Scatchard replot of the same data. In the 1-site fit depicted, the background values, determined by the LIGAND computer program, are subtracted. Data are from a representative experiment performed in duplicate. Essentially identical results were obtained in 14 independent experiments. No analysis of saturation data using the LIGAND program yielded a statistically significant 2-site fit of the Scatchard plot.

Dissociation of $\omega\left[{ }^{125} \mathrm{I}\right] \mathrm{CTX}$ was examined by incubating the toxin with rat brain membranes to equilibrium, whereupon dissociation was initiated either by the addition of $100 \mathrm{nM}$ unlabeled $\omega$-CTX (Fig. $3 B$ ) or 50 -fold dilution of the buffer (data not shown), and residual binding was measured at several time intervals. The rate of dissociation of $\omega\left[{ }^{[25} \mathrm{I}\right] \mathrm{CTX}$ is essentially the same by both of these techniques, suggesting the absence of cooperative interactions. When plotted on semilogarithmic paper, the dissociation is linear with $50 \%$ dissociation apparent at about $12 \mathrm{hr}$. The calculated rate constant for dissociation $\left(k_{-1}\right)$ is $0.001 \mathrm{~min}^{-1}$ both by measurements utilizing excess ligand (Fig. $3 B$ ) or infinite dilution (data not shown). In some experiments we attempted to monitor dissociation at $4^{\circ} \mathrm{C}$. Less than $20 \%$ dissociation was apparent at $24 \mathrm{hr}$. The kinetically derived dissociation constant, obtained from the ratio $k_{-1} / k_{1}$ is $40 \mathrm{fm}$, a value substantially lower than the $K_{D}$ from equilibrium experiments. The discrepancy between $K_{D}$ values determined in equilibrium and kinetic experiments might reflect irreversible or pseudoirreversible ligand binding with some of the dissociation deriving from decomposition of the ligand.

\section{Influences of peptides and drugs on $\omega\left[{ }^{125} I\right] C T X$ binding}

$\omega$-CTX itself is the most potent competitor for $\omega\left[{ }^{125} I\right] \mathrm{CTX}$ binding, with $50 \%$ inhibition apparent at $0.061 \mathrm{~nm}$ (Table 1). The MVIA toxin, derived from a different species of snail than $\omega$-CTX, but similar in chemical structure and toxicity, has an $\mathrm{IC}_{50}$ of $0.5 \mathrm{~nm}$.

Rat myelin basic protein and polylysine $(22 \mathrm{kDa})$ have $\mathrm{IC}_{50}$ values of 2 and $5 \mathrm{nM}$, respectively. Whereas $\omega$-CTX reduces binding in a competitive fashion, Scatchard analysis indicates noncompetitive inhibition by both myelin basic protein and polylysine (Fig. 4). Myelin basic protein and polylysine exert similarly potent inhibition of ligand binding to a cannabinoid receptor (Nye et al., 1988), presumably reflecting complementary charged sites on the receptors. 
Table 1. Effects of drugs, peptides, and proteins on $\omega\left[{ }^{125} I\right] C T X$ binding to rabbit sympathetic ganglia membranes and intact and solubilized rat forebrain membrane

\begin{tabular}{|c|c|c|c|}
\hline & \multicolumn{3}{|l|}{$\underline{\mathrm{IC}_{50}(\mathrm{nM})}$} \\
\hline & \multicolumn{2}{|l|}{ Rat forebrain } & \multirow{2}{*}{$\begin{array}{l}\text { Rabbit } \\
\text { sympathetic } \\
\text { ganglia } \\
\text { membranes }\end{array}$} \\
\hline & Membrane & Solubilized & \\
\hline \multicolumn{4}{|l|}{ Conus peptides } \\
\hline $\begin{array}{l}\omega \text {-CTX GVIA, } \\
\text { native }\end{array}$ & 0.061 & 0.069 & 0.092 \\
\hline $\begin{array}{l}\omega \text {-CTX GVIA, } \\
\text { synthesized }\end{array}$ & 0.090 & 0.105 & 0.120 \\
\hline $\begin{array}{l}\omega-\text { CTX MVIIA, } \\
\text { native }\end{array}$ & 0.5 & N.D. & N.D. \\
\hline \multicolumn{4}{|l|}{ Polycationic proteins } \\
\hline $\begin{array}{l}\text { Rat myelin basic } \\
\text { protein }\end{array}$ & 2 & 21 & N.D. \\
\hline Polysine (22K) & 5 & 15 & 15 \\
\hline \multicolumn{4}{|c|}{ Aminoglycoside antibiotics } \\
\hline Amikacin & 15,000 & N.D. & 14,000 \\
\hline Gentamycin & 10,000 & N.D. & 18,000 \\
\hline Kanamycin & 200,000 & 370,000 & 240,000 \\
\hline Neomycin & 3,000 & 6,000 & 7,000 \\
\hline Streptomycin & 51,000 & 63,000 & 65,000 \\
\hline Tobramycin & 18,000 & N.D. & 27,000 \\
\hline \multicolumn{4}{|c|}{ L-channel $\mathrm{Ca}^{2+}$ antagonists } \\
\hline $\begin{array}{l}\text { Verapamil } \\
(-) \text { Desmethoxy- }\end{array}$ & $>10,000$ & $>10,000$ & $>10,000$ \\
\hline $\begin{array}{l}\text { verapamil } \\
(+) \text { Desmethoxy- }\end{array}$ & $>10,000$ & $>10,000$ & $>10,000$ \\
\hline verapamil & $>10,000$ & N.D. & $>10,000$ \\
\hline Nitrendipine & $>10,000$ & $>10,000$ & $>10,000$ \\
\hline$(+) P N 200-110$ & $>10,000$ & N.D. & $>10,000$ \\
\hline Diltiazem & $>10,000$ & $>10,000$ & $>10,000$ \\
\hline Fostedil & $>10,000$ & N.D. & $>10,000$ \\
\hline
\end{tabular}

The effects of toxin peptides, polycationic proteins, aminoglycoside antibiotics and $\mathrm{L}$-channel $\mathrm{Ca}^{2+}$ antagonists on $\left.\omega^{[25}{ }^{22}\right] \mathrm{CTX}$ were assessed in rat brain, membrane and solubilized, and rabbit sympathetic ganglion membranes. Data are $\mathrm{IC}_{50}$ values from a single representative experiment replicated on 6 occasions for toxin peptides, 4 occasions for polycationic proteins, 4 occasions for aminoglycosides, and 3 occasions for $\mathrm{Ca}^{2+}$ antagonists.

The aminoglycoside antibiotics exert potent neurotoxicity, which is reversed by calcium (Lietman, 1985; Sande and Mandell, 1985). In preliminary experiments we have found that the aminoglycoside antibiotics inhibit ${ }^{45} \mathrm{Ca}^{2+}$ uptake into synaptosomes through voltage-dependent calcium channels in proportion to their relative neurotoxicity. A series of 6 aminoglycoside antibiotics all inhibit $\left.\omega{ }^{[25} \mathrm{I}\right] \mathrm{CTX}$ binding. Scatchard analysis indicates noncompetitive inhibitory patterns (Fig. 4). Neomycin, which is the most neurotoxic of these drugs, is the most potent inhibitor of ligand binding.

Calcium antagonist drugs which are known to act through the L subtype of calcium channels all fail to inhibit $\omega\left[{ }^{125} I\right] C T X$ binding at $10 \mu \mathrm{M}$. These findings confirm previous observations with lower specific activity $\omega\left[{ }^{125} I\right] C T X$ (Abe et al., 1986; Cruz and Olivera, 1986).

By contrast to the potent influences upon toxin binding of myelin basic protein and polylysine, these substances do not inhibit $\left[{ }^{3} \mathrm{H}\right]$ nitrendipine binding to brain membranes at $10 \mu \mathrm{M}$ concentration. Similarly, the aminoglycoside antibiotics at $1 \mathrm{mM}$
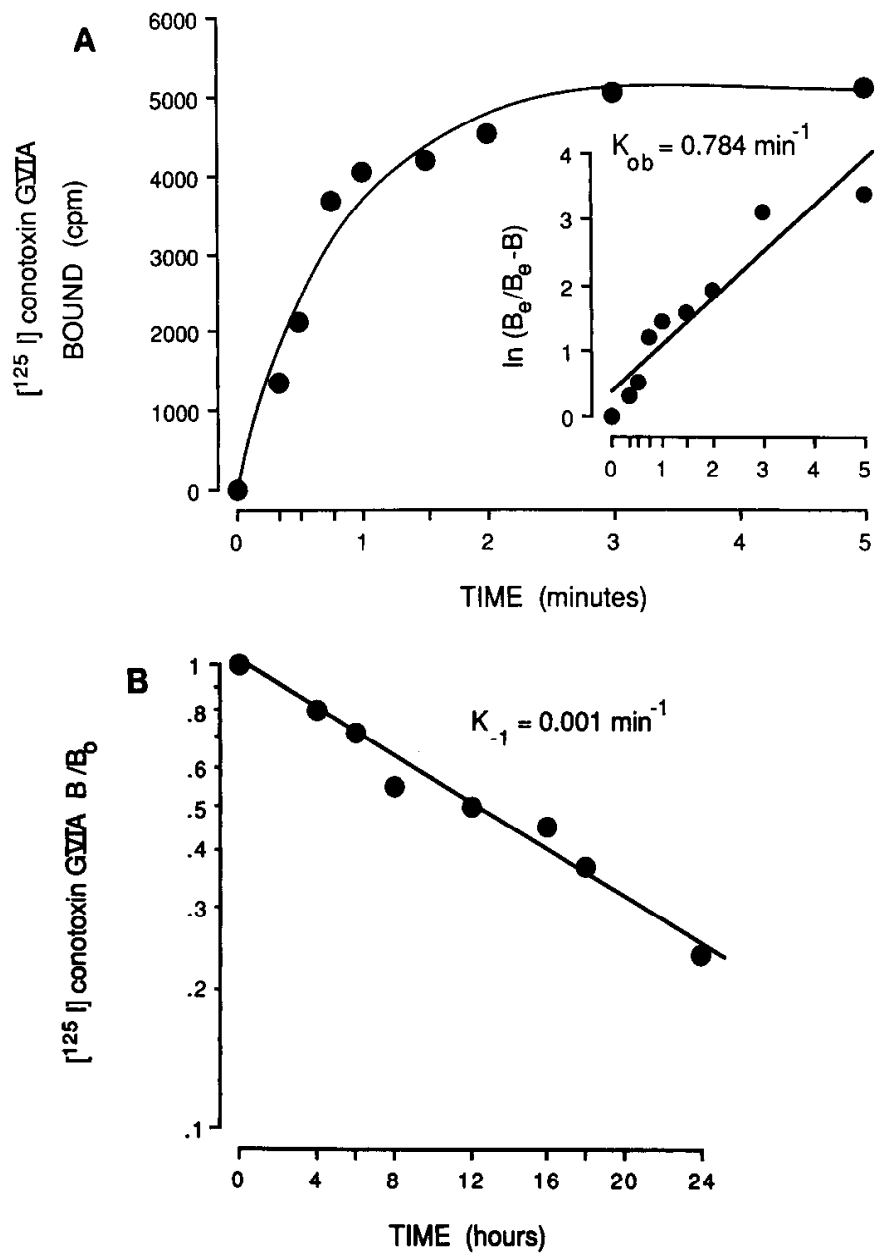

Figure 3. Association $(A)$ and dissociation $(B)$ of $\omega\left[{ }^{125} \mathrm{I}\right] \mathrm{CTX}$ with rat forebrain membranes. Total and nonspecific $\omega\left[{ }^{125} I\right] C T X$ binding to brain membranes was determined as in Materials and Methods. $A$, Specific $\omega\left[{ }^{125} I\right] C T X$ binding in cpm plotted against duration of incubation. The concentration of $\omega\left[{ }^{125} \mathrm{I}\right] \mathrm{CTX}$ was $28 \mathrm{pM}$. Inset, Replot of the same data: $\ln \left(B_{e} / B_{e}-B\right)$ versus time, where $B_{c}=$ bound $\omega\left[{ }^{123} I\right] C T X$ at equilibrium and $B=$ bound toxin at a particular time point. The replot is linear and is used to calculate $K_{\mathrm{ob}} . B$, The dissociation of $\omega\left[{ }^{125} \mathrm{I}\right] \mathrm{CTX}$ from brain membranes equilibrated with $25 \mathrm{pm} \omega^{\left[{ }^{125} \mathrm{I}\right] \mathrm{CTX}}$ for $30 \mathrm{~min}$. Dissociations were initiated with $100 \mathrm{~nm}$ unlabeled toxin. Each point of the dissociation has a set of controls (total and blank) equilibrated for the entire duration of the dissociation. Blanks (nonspecific binding) were determined in the presence of $100 \mathrm{~nm}$ unlabeled $\omega$-CTX. Results are the means of duplicate determinations. The experiment was replicated on 3 occasions with similar results.

fail to affect $\left[{ }^{3} \mathrm{H}\right]$ nitrendipine binding, except for streptomycin whose $\mathrm{IC}_{50}$ is $330 \mu \mathrm{M}$.

\section{Brain regional and tissue distribution of $\left.\omega{ }^{125} I\right] C T X$ GVIA binding}

Voltage-dependent calcium channels are not uniformly distributed throughout the brain. The L-type channels labeled with $\left[{ }^{3} \mathrm{H}\right]$ nitrendipine demonstrate heterogeneous distributions (Table 2) with maximal binding in the hippocampus, lowest binding in the brain stem, and intermediate levels in the cerebral cortex, confirming previous results obtained by both biochemical (Gould et al., 1982) and autoradiographic techniques. The distribution of $\omega\left[{ }^{125} \mathrm{I}\right] \mathrm{CTX}$ binding differs substantially from that of $\left[{ }^{3} \mathrm{H}\right]$ nitrendipine binding (Gould et al., 1985). More than 10fold variations are apparent between the highest levels in the 
Table 2. Distribution of $\omega\left[{ }^{125} I\right] C T X$ and $\left[{ }^{3} H \mid\right.$ nitrendipine binding in different neuronal regions

\begin{tabular}{|c|c|c|c|c|}
\hline \multirow[b]{2}{*}{ Tissue } & \multicolumn{2}{|c|}{$\omega\left[{ }^{125} \mathrm{I}\right] \mathrm{CTX}$} & \multicolumn{2}{|c|}{$\left[{ }^{3} \mathrm{H}\right]$ Nitrendipine } \\
\hline & $\begin{array}{l}K_{D} \\
\text { (pM) }\end{array}$ & $\begin{array}{l}B_{\max } \\
\text { (pmol/mg } \\
\text { protein) }\end{array}$ & $\begin{array}{l}K_{D} \\
(\mathrm{pM}) \\
\end{array}$ & $\begin{array}{l}B_{\max } \\
\text { (pmol/mg } \\
\text { protein) }\end{array}$ \\
\hline Cerebral cortex & 67 & 8.3 & 133 & 0.149 \\
\hline Cerebellum & 54 & 3.7 & 124 & 0.046 \\
\hline Thalamus/hypothalamus & 82 & 3.6 & 115 & 0.103 \\
\hline Corpus striatum & 71 & 2.0 & 129 & 0.149 \\
\hline Hippocampus & 46 & 6.4 & 110 & 0.172 \\
\hline Midbrain & 113 & 3.5 & - & $<0.01$ \\
\hline Brain stem & 40 & 0.55 & - & $<0.01$ \\
\hline Pituitary & 313 & 2.2 & N.D. & N.D. \\
\hline Rabbit sympathetic ganglion & 150 & 1.1 & N.D. & N.D. \\
\hline
\end{tabular}

Other tissue examined without detectable $\omega\left[^{125}\right.$ I]CTX binding include kidney, heart, trachea, bladder, vas deferens, spleen, lung, hindleg skeletal muscle, aorta, testes, and liver

cerebral cortex and the lowest values in the brain stem. The hippocampus and cerebral cortex have fairly similar levels, whereas next highest values in the cerebellum and hypothalamus-thalamus and midbrain are less than half those of the cortex.

The $K_{D}$ values for $\omega\left[{ }^{125} \mathrm{I}\right] \mathrm{CTX}$ binding are similar in most brain regions, though the $K_{D}$ level is significantly higher in the midbrain than in other areas (Table 2). The $K_{D}$ value in the pituitary is higher than in the principal brain areas.

We examined a wide range of peripheral tissues for $\omega\left[{ }^{125} \mathrm{I}\right] \mathrm{CTX}$ binding. Substantial levels of saturable high-affinity binding sites are detected only in rabbit sympathetic ganglia membranes (Table 2). The $K_{D}$ value for $\omega\left[{ }^{125} \mathrm{I}\right] \mathrm{CTX}$ in this tissue is similar to valucs in brain membranes, suggesting that the same or closely similar sites are labeled. However, binding site density is lower in sympathetic ganglia than in any of the brain regions examined except for brain stem. Since frozen ganglia were employed and $\omega\left[{ }^{125} \mathrm{I}\right] \mathrm{CTX}$ binding is lower in frozen than fresh brain, values for ganglia binding may be underestimates. The drug specificity of the $\omega\left[{ }^{125} I\right]$ CTX site in ganglia membranes is similar to the site in rat forebrain (Table 1). None of the non-neuronal tissues examined have detectable levels of $\omega\left[{ }^{125} \mathrm{I}\right] \mathrm{CTX}$ binding (Table 2).

\section{Effect of cations on $\omega{ }^{[25}$ I]CTX GVIA binding}

If $\omega$-CTX labels voltage-dependent calcium channels, one might anticipate it to be influenced by physiological concentrations of calcium. However, in an earlier study, $30 \mathrm{~mm}$ calcium was required to reduce binding substantially (Cruz and Olivera, 1986). In the present study, employing much lower ligand and tissue concentrations, we detect more potent effects of calcium (Table 3 ). Fifty percent inhibition of binding is apparent with $0.2 \mathrm{~mm}$ calcium. Similar effects are observed with the wide range of divalent cations. The most potent inhibitors of binding are $\mathrm{La}^{3+}$ and $\mathrm{Hg}^{2+}$, with respective $\mathrm{IC}_{50}$ values of 0.09 and $0.03 \mathrm{~mm}$. Scatchard analysis indicates that the inhibitory effect of calcium is noncompelitive (Fig. 4). Similar cation effects are observed in $\omega\left[{ }^{125} \mathrm{I}\right] \mathrm{CTX}$ binding to sympathetic ganglia.

\section{Solubilization of $\left.{ }^{[25}{ }^{25}\right] C T X$ GVIA binding sites}

To ascertain whether ligand binding is retained in solubilized membranes, we treated rat brain membranes with $1 \%$ CHAPS
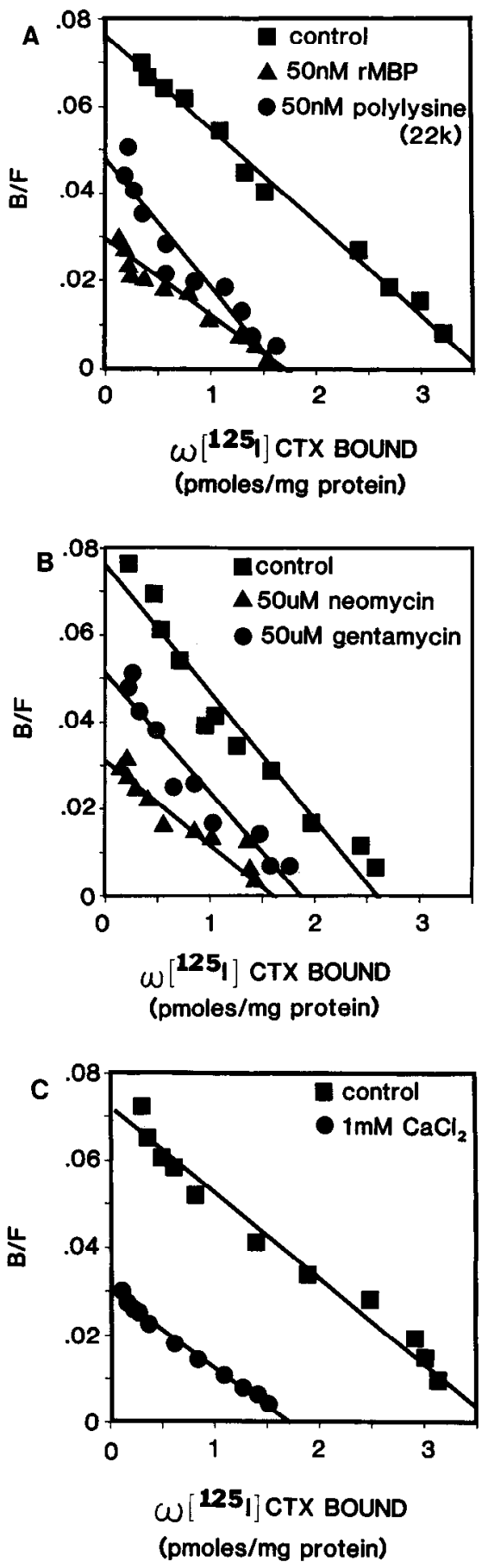

Figure 4. The effects of various agents on saturation of $\left.\omega{ }^{125} \mathrm{I}\right] \mathrm{CTX}$ binding to brain membranes. $A$, Effects of no additive (filled squares), $50 \mathrm{nM}$ rat myelin basic protein (filled triangles), or $50 \mathrm{nM} 22 \mathrm{~K}$ polylysine (filled circles). $B$, Effects of no additive ( filled squares), $50 \mu \mathrm{M}$ neomycin (filled triangles), or $50 \mu \mathrm{M}$ gentamycin (filled circles). C, Effects of no additive (filled squares) or $1 \mathrm{~mm} \mathrm{CaCl}_{2}$ (filled circles).

or Triton X-100. Both solubilized preparations display substantial levels of specific $\omega\left[^{125} \mathrm{I}\right] \mathrm{CTX}$ binding at $25^{\circ} \mathrm{C}$.

We have conducted routine assays with CHAPS. Similar binding levels occur in preparations solubilized with $0.5,0.75$, and $1.0 \%$ CHAPS, and $0.75 \%$ CHAPS is employed routincly. $\omega\left[{ }^{125} \mathrm{I}\right] \mathrm{CTX}$ binding is linear with tissue protein over the range $1-100 \mu \mathrm{g}$ (data not shown). Essentially all $\omega\left[{ }^{125} \mathrm{I}\right] \mathrm{CTX}$ binding in the membranes is recovered in the solubilized preparations. 


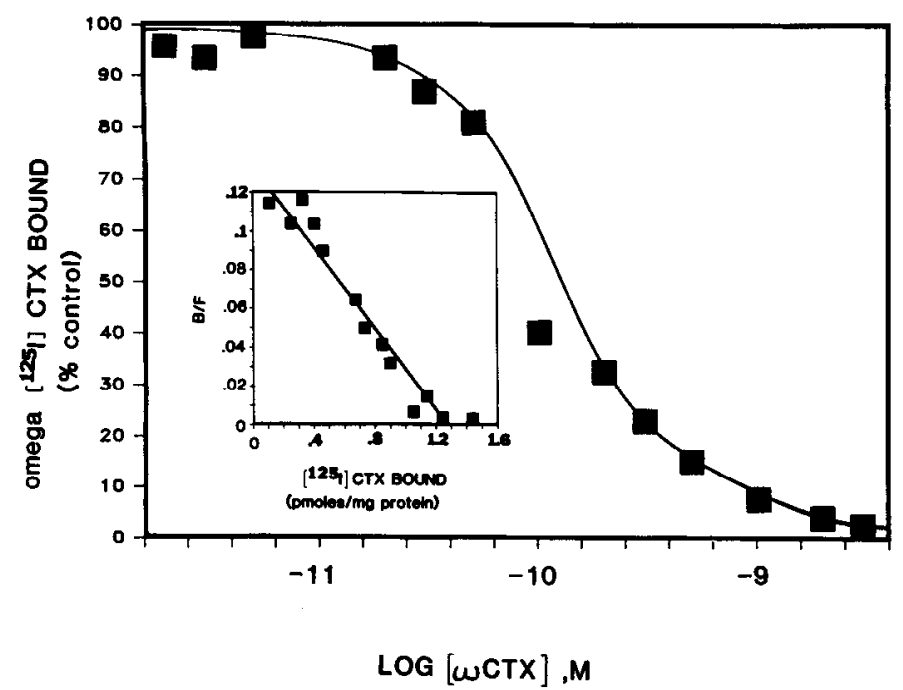

Figure 5. Saturation analysis of $\omega\left[{ }^{[25} \mathrm{I}\right] \mathrm{CTX}$ binding to solubilized rat forebrain membranes. Concentration of $\omega\left[{ }^{125} I\right] C T X$ was 34 pM. Inset, Scatchard replot of the same data. Data are from a representative experiment performed in duplicate. Essentially identical results were obtained in 6 independent experiments performed on different days with different solubilized preparations.

Scatchard analysis reveals a single population of binding sites with a $K_{D}$ of $60 \mathrm{pM}$, essentially the same as observed in intact membranes (Fig. 5).

Additional evidence that solubilizcd binding sites are the same as those that are in the membrane includes the closely similar effects of peptides, drugs, and cations on binding in solubilized

\section{Table 3. Effects of cations on $\omega\left[{ }^{125} I\right] C T X$ binding to rabbit} sympathetic ganglia membranes and intact and solubilized rat forebrain membranes

$$
\underline{\mathrm{IC}_{50}(\mathrm{~mm})}
$$

\begin{tabular}{lll}
\hline Rat forebrain & & $\begin{array}{l}\text { Rabbit } \\
\text { sympathetic } \\
\text { ganglia } \\
\text { membranes }\end{array}$ \\
\hline Membrane & Solubilized & \begin{tabular}{l} 
membin \\
\hline
\end{tabular}
\end{tabular}

$\begin{array}{cccc}\text { Group IA } & & & \\ \mathrm{NaCl} & 31 & 35 & 33 \\ \mathrm{KCl} & 42 & 30 & 38 \\ \mathrm{LiCl} & 35 & 50 & 33 \\ \mathrm{CsCl} & 47 & 40 & 42\end{array}$

Group IIA

$\begin{array}{llll}\mathrm{CaCl}_{2} & 0.22 & 0.20 & 0.25 \\ \mathrm{BaCl}_{2} & 0.20 & 0.14 & 0.17 \\ \mathrm{SrCl}_{2} & 0.37 & 0.19 & 0.21 \\ \mathrm{MgCl}_{2} & 0.60 & 0.85 & 0.76 \\ \mathrm{ransition} \text { and lanthanide series } & & \\ \mathrm{CoCl}_{2} & 0.15 & 0.16 & 0.11 \\ \mathrm{CdCl}_{2} & 0.21 & 0.32 & 0.25 \\ \mathrm{LaCl}_{3} & 0.09 & 0.05 & 0.07 \\ \mathrm{~Pb}_{\left(\mathrm{NO}_{3}\right)_{2}} & 0.34 & 0.52 & 0.47 \\ \mathrm{HgCl}_{2} & 0.03 & \text { N.D. } & 0.06 \\ \mathrm{CuCl}_{2} & 0.02 & \text { N.D. } & \text { N.D. } \\ \mathrm{NiCl}_{2} & 0.35 & 0.57 & 0.53\end{array}$

The effects of 8-16 concentrations of various cations were examined in triplicate on $\omega\left[{ }^{[25} \mathrm{I}\right] \mathrm{CTX}$ binding. Data are from a representative experiment replicated 3 times.
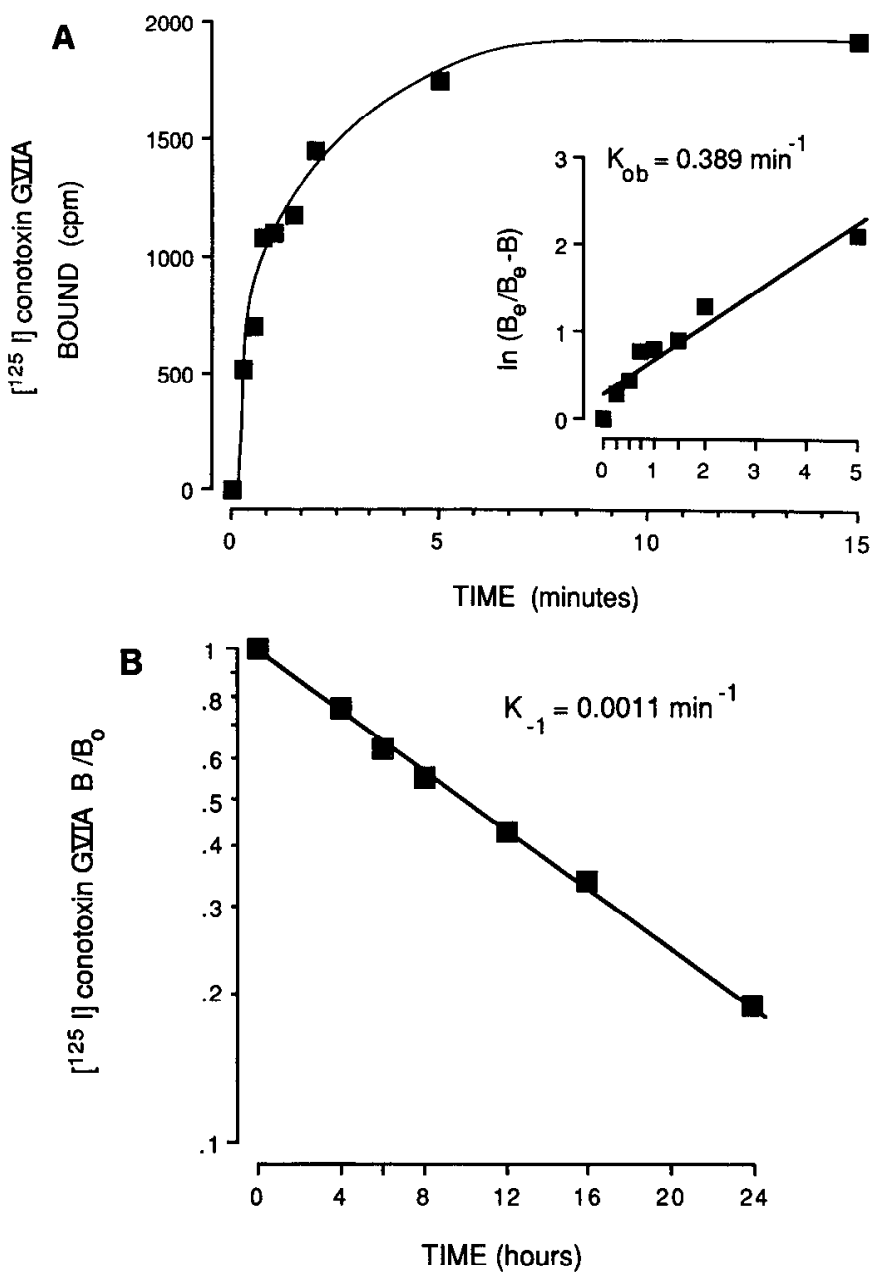

Figure 6. Association and dissociation of $\omega[125 I] \mathrm{CTX}$ to solubilized rat forebrain membranes. Total and nonspecific $\left.\omega{ }^{[25} I\right] C T X$ binding to brain membranes was assayed as described in Materials and Methods. $A$, Specific $\omega\left[{ }^{125} I\right] C T X$ binding in $\mathrm{cpm}$ plotted against the duration of incubation. The concentration of $\left.\omega^{[125}{ }^{12}\right]$ CTX was $33 \mathrm{pM}$. Inset, Same data plotted as described in the legend to Figure 3. B. Dissociation of $\omega\left[{ }^{125} I\right] C T X$ from solubilized brain membranes equilibrated with $21 \mathrm{pm}$ $\omega\left[{ }^{125} \mathrm{I}\right] \mathrm{CTX}$ for $30 \mathrm{~min}$. Results are the mcans of duplicates. These experiments were repeated on 2 occasions with similar results.

and particulate fractions (Tables 1 and 3). The association and dissociation rates of $\omega\left[{ }^{125} \mathrm{I}\right] \mathrm{CTX}$ in solubilized preparation are similar to those in crude membranes (Fig. 6).

\section{Discussion}

The main finding of this study is the identification of unique, very high affinity binding sites for $\omega\left[{ }^{[25}[] C T X\right.$ in rat brain membranes whose properties fit those of voltage-dependent calcium channels of the $\mathrm{N}$ subtype. These sites appear to mediate the marked effects of $\omega$-CTX upon calcium passage through voltagesensitive channels. Thus, in synaptosomes we observed halfmaximal effects of $\omega$-CTX on calcium flux at 50 pM, closely similar to the $K_{\nu}$ of $\omega$-CTX for the binding sites (Reynolds et al., 1986). Previous study in which $\omega$-CTX had about 100 -fold lesser affinity for binding sites in chick brain synaptosomes may reflect the use of much lower specific activity toxins so that the lowest concentration of radiolabeled ligand employed was 0.1 $\mathrm{nM}_{\mathrm{M}}$, though there may also be species differences and variations in tissue preparation (Cruz and Olivera, 1986). 
Further evidence that $\omega\left[{ }^{125} I\right] C T X$ binding involves voltagedependent calcium channels stems from the ability of calcium to inhibit binding at physiological extracellular concentrations. The noncompctitive naturc of calcium's inhibition fits with the notion that the $\omega$-CTX binding site is not identical to the calcium pore but is linked to it allosterically.

Three subtypes of voltage-dependent calcium channels have been differentiated by Tsien and associates (Nowycky et al., 1985). The principal calcium antagonist drugs employed clinically act at the L subtype, which is implicated in contractility of cardiac and smooth muscle. Calcium-dependent neurotransmitter release at synapses in the CNS appears to be associated primarily with the $\mathrm{N}$ channels and is not markedly affected by the major calcium antagonist drugs (Turner and Goldin, 1985; Reynolds et al., 1986; Miller, 1987). The functions of the T channel are unclear. $\omega$-CTX influences $\mathrm{L}$ and $\mathrm{N}$ but not $\mathrm{T}$ channels (McCleskey et al., 1987). $\omega$-CTX inhibits neurotransmitter release (Kerr and Yoshikami, 1984) and in our studies (Reynolds et al., 1986) does so with a potency comparable to its $K_{D}$ for the $\omega$-CTX binding sites. The binding of $\omega\left[{ }^{125} I\right] C T X$ observed here appears to involve primarily or exclusively the $\mathrm{N}$-subtype channels for 2 reasons. First, the binding sites are uninfluenced by the calcium antagonist drugs that act at $L$ channels. Second, rat brain membranes possess about 30 times more $\omega$-CTX binding sites than dihydropyridine binding sites. Thus, even if $\omega\left[{ }^{125} I\right] C T X$ bound to both channel subtypes, interactions with the L-type channel might not be detectable. The potent, selective interactions of $\omega$-CTX with the N-type calcium channel afford a valuable probe for physiological processes associated with this type of calcium channel.

\section{References}

Abe, T., K. Koyano, H. Saisu, Y. Nishiuchi, and S. Sakakibara (1986) Binding of $\omega$-conotoxin to receptor sites associated with voltage-sensitive calcium channel. Neurosci. Lett. 71: 203-208.

Cruz, L. J., and B. M. Olivera (1986) Calcium channel antagonists. $\omega$-conotoxin defines a new high affinity site. J. Biol. Chem. 261:62306233.

Cruz, L. J., D. S. Johnson, and B. M. Olivera (1987) Characterization of the $\omega$-conotoxin target. Evidence for tissue-specific heterogeneity in calcium channel types. Biochemistry $26: 820-824$.

Gould, R. J., K. M. M. Murphy, and S. H. Snyder (1982) $\left[{ }^{3} \mathrm{H}\right] N$ itrendipine-labeled calcium channels discriminate inorganic calcium agonists and antagonists. Proc. Natl. Acad. Sci. USA 79: 3656-3660.

Gould, R. J., K. M. M. Murphy, and S. H. Snyder (1985) Autoradiographic localization of calcium channel antagonist receptors in rat brain with ${ }^{3} \mathrm{H}$-nitrendipine. Brain Res. 330: 217-223.

Kerr, L. M., and D. Yoshikami (1984) A venom peptide with a novel presynaptic blocking action. Nature 308: 282-284.

Kobayashi, J., H. Nakamura, Y. Hirata, and Y. Ohizumi (1982) Effect of venoms from conidae on skeletal, cardiac and smooth muscles. Toxicon 20: 823-830.

Lietman, P. S. (1985) Aminoglycosides and spectinomycin: Aminocyclitols. In Principles and Practices of Infectious Diseases, G. L. Mandell, R. G. Douglas, and J. E. Bennett, eds., pp. 192-206, Wiley, New York.

McCleskey, E. W., A. P. Fox, D. H. Feldman, L. J. Cruz, B. M. Olivera, R. W. Tsien, and D. Yoshikami (1987) $\omega$-Conotoxin: Direct and persistent blockade of specific types of calcium channels in neurons but not muscle. Proc. Natl. Acad. Sci. USA 84: 4327-4331.

Miller, R. J. (1987) Multiple calcium channels and neuronal function. Science 235: 46-52.

Murphy, K. M. M., R. J. Gould, B. L. Largent, and S. H. Snyder (1983) A unitary mechanism of calcium antagonist drug action. Proc. Natl. Acad. Sci. IJSA 80: 860-864.

Nilius, B., P. Hess, J. B. Lansman, and R. W. Tsien (1985) A novel type of cardiac calcium channel in ventricular cells. Nature 316:443446.

Nowycky, M. C., A. P. Fox, and R. W. Tsien (1985) Three types of neuronal calcium channel with different calcium agonist sensitivity. Nature 316: 440-443.

Nye, J. S., S. Voglmaier, R. E. Martenson, and S. H. Snyder (1988) Myelin basic protein is an endogenous inhibitor of the high affinity cannabinoid binding site in brain. J. Neurochem. 50:1170-1178.

Olivera, B. M., J. M. McIntosh, L. J. Cruz, F. A. Luque, and W. R. Gray (1984) Purification and sequence of presynaptic peptide toxin from Conus geographus venom. Biochemistry 23: 3090-3095.

Olivera, B. M., W. R. Gray, R. Zekus, J. M. McIntosh, J. Varga, J. Rivier, V. de Santos, and L. J. Cruz (1985) Peptide neurotoxins from fish-hunting cone snails. Science 230: 1338-1343.

Reynolds, I. J., J. A. Wagner, S. H. Snyder, S. A. Thayer, B. M. Olivera, and R. J. Miller (1986) Brain voltage-sensitive calcium channel subtypes differentiated by $\omega$-conotoxin fraction GVIA. Proc. Natl. Acad. Sci. USA 83: 8804-8807.

Sande, M. A., and G. L. Mandell (1985) Antimicrobial agents: The aminoglycosides. In The Pharmacological Basis of Therapeutics, pp. 1150-1169, Macmillan, New York.

Turner, T. J., and S. M. Goldin (1985) Calcium channels in rat brain synaptosomes: Identification and pharmacological characterization. J. Neurosci. 5: 841-849. 